\title{
Noninvasive Quantitative Assessment of Pulmonary Blood Flow with ${ }^{18}$ F-FDG PET
}

\author{
Céline Pouzot ${ }^{1-3}$, Jean-Christophe Richard ${ }^{2-4}$, Antoine Gros $^{4}$, Nicolas Costes ${ }^{5}$, Franck Lavenne ${ }^{5}$, Didier Le Bars ${ }^{5}$, \\ and Claude Guerin ${ }^{2-4}$ \\ ${ }^{1}$ Service Siamu, VetAgro Sup, Campus Vétérinaire de Lyon, Marcy l'Etoile, France; ${ }^{2}$ Université Lyon 1, Lyon, France; ${ }^{3}$ CREATIS, \\ INSERM 1044, CNRS 5220, Villeurbanne, France; ${ }^{4}$ Service de Réanimation Médicale, Hôpital de la Croix Rousse, Hospices Civils de \\ Lyon, Lyon, France; and ${ }^{5}$ CERMEP, Imagerie du Vivant, Hôpital Neurologique, Lyon, France
}

Pulmonary blood flow (PBF) is a critical determinant of oxygenation during acute lung injury (ALI). PET/CT with ${ }^{18} \mathrm{~F}-\mathrm{FDG}$ allows the assessment of both lung aeration and neutrophil inflammation as well as an estimation of the regional fraction of blood (FB) if compartmental modeling is used to quantify ${ }^{18} \mathrm{~F}-\mathrm{FDG}$ pulmonary uptake. The aim of this study was to validate the use of FB to assess PBF, with PET and compartmental modeling of ${ }^{15} \mathrm{O}-\mathrm{H}_{2} \mathrm{O}$ kinetics as a reference method, in both control animals and animals with ALI. For the purpose of studying a wide range of PBF values, supine and prone positions and various positive end-expiratory pressures (PEEPs) and tidal volumes $\left(V_{T} s\right)$ were selected. Methods: Pigs were randomized into 3 groups in which ALI was induced by $\mathrm{HCl}$ inhalation: pigs studied in the supine position with a low PEEP $(5 \pm 3$ [mean $\pm \mathrm{SD}$ ] $\mathrm{cm}$ of $\left.\mathrm{H}_{2} \mathrm{O} ; n=9\right)$ or a high PEEP $(12 \pm 1 \mathrm{~cm}$ of $\mathrm{H}_{2} \mathrm{O} ; n=8$ ) and pigs studied in the prone position with a low PEEP $\left(6 \pm 3 \mathrm{~cm}\right.$ of $\left.\mathrm{H}_{2} \mathrm{O} ; n=9\right)$. Also included were a control group that did not have ALI $(n=6)$ and 2 additional groups ( $n=6$ each) that had a high $\mathrm{V}_{\mathrm{T}}$ to maintain a transpulmonary pressure of greater than or equal to $35 \mathrm{~cm}$ of $\mathrm{H}_{2} \mathrm{O}$ and that either received $\mathrm{HCl}$ inhalation or did not receive $\mathrm{HCl}$ inhalation. $\mathrm{PBF}$ and $\mathrm{FB}$ were measured with $\mathrm{PET}$ and compartmental modeling of ${ }^{15} \mathrm{O}-\mathrm{H}_{2} \mathrm{O}$ and ${ }^{18} \mathrm{~F}-\mathrm{FDG}$ kinetics in 10 lung regions along the anterior-to-posterior lung dimension, and both were expressed in each region as a fraction of their values in the whole lung. Results: PBF and FB were strongly correlated $\left(R^{2}=\right.$ 0.9 ), with a slope of the regression line close to unity and a negligible intercept. The mean difference between PBF and FB was 0 , and the $95 \%$ limits of agreement were -0.035 to 0.035 . This good agreement between methods was obtained in both normal and injured lungs and under a wide range of $\mathrm{V}_{\mathrm{T}}$, PEEP, and regional $\mathrm{PBF}$ values (7-71 mL/kg, 0-15 cm of $\mathrm{H}_{2} \mathrm{O}$, and $24-603 \mathrm{~mL} \cdot \mathrm{min}^{-1} .100 \mathrm{~mL}$ of lung $^{-1}$, respectively). Conclusion: FB assessed with ${ }^{18} \mathrm{~F}-\mathrm{FDG}$ is a good surrogate for PBF in both normal animals and animals with ALI. PET/CT has the potential to be used to study ventilation, perfusion, and lung inflammation with a single tracer.

Key Words: acute lung injury; PET; ${ }^{18}$ F-FDG; pulmonary blood flow

J Nucl Med 2013; 54:1653-1660

DOI: 10.2967/jnumed.112.116699

\footnotetext{
Received Nov. 3, 2012; revision accepted Mar. 26, 2013.

For correspondence or reprints contact: Claude Guerin, Service de Réanimation Médicale, 103 Grande Rue de la Croix Rousse, 69004 Lyon, France.

E-mail: claude.guerin@chu-lyon.fr

Published online Aug. 1, 2013.

COPYRIGHT (C) 2013 by the Society of Nuclear Medicine and Molecular Imaging, Inc.
}

A

ssessment of lung perfusion is critical for evaluating the pathophysiology of gas exchange abnormalities and can be performed noninvasively with several imaging tools: SPECT (1), PET (2-4), 4-dimensional CT $(5,6)$, and MR imaging $(7,8)$. PET is particularly attractive because of its high sensitivity and ability to track many other lung pathophysiologic processes (in addition to perfusion), such as ventilation $(9,10)$, ventilation-to-perfusion ratio $(11,12)$, and inflammation $(13,14)$. Pulmonary blood flow (PBF) is usually assessed with PET and compartmental modeling of ${ }^{15} \mathrm{O}$-labeled water $\left({ }^{15} \mathrm{O}-\mathrm{H}_{2} \mathrm{O}\right)(2)$ or ${ }^{13} \mathrm{~N}_{-} \mathrm{N}_{2}$ (15) kinetics, with high reliability when compared with microspheres (2-4). However, these tracers have been used only for research purposes and are not readily available in every PET facility because their short half-life requires a cyclotron on site.

In contrast, ${ }^{18} \mathrm{~F}-\mathrm{FDG}$ is used widely to quantify lung metabolic activity. Such activity has been taken as a surrogate for neutrophil activation during acute lung injury (ALI) $(13,14)$. In addition to the net ${ }^{18} \mathrm{~F}-\mathrm{FDG}$ uptake rate within the lung, some compartmental modeling techniques $(16,17)$ estimate the regional fraction of blood (FB), accounting for the contribution of intravascular ${ }^{18} \mathrm{~F}$ FDG to pulmonary radioactivity assessed by PET within each lung region. Because the spatial resolution of PET is relatively poor, vascular structures are included within lung regions of interest, and FB represents the volume of blood relative to the total volume of a lung region and is usually expressed in milliliters of blood per 100 milliliters of lung.

We hypothesized that FB should be the main determinant of PBF. The aim of this study was to evaluate the reliability of FB for evaluating PBF with PET; compartmental modeling of ${ }^{15} \mathrm{O}-\mathrm{H}_{2} \mathrm{O}$ kinetics assessed with PET was used as the reference method. A wide range of pulmonary perfusion values was investigated across measurements obtained in the supine and prone positions and at various levels of applied positive end-expiratory pressures (PEEPs) and tidal volumes $\left(\mathrm{V}_{\mathrm{T}} \mathrm{s}\right)$.

\section{MATERIALS AND METHODS}

This study was approved by the Institutional Review Board of Université Lyon I for the care of animal subjects and was performed with 44 female pigs as part of an experimental investigation aimed at testing various ventilatory strategies and posture with regard to lung inflammation assessed by ${ }^{18} \mathrm{~F}-\mathrm{FDG}(18)$.

\section{Animal Preparation}

The pigs were anesthetized with propofol and fentanyl, tracheotomized, and mechanically ventilated in the volume-controlled 


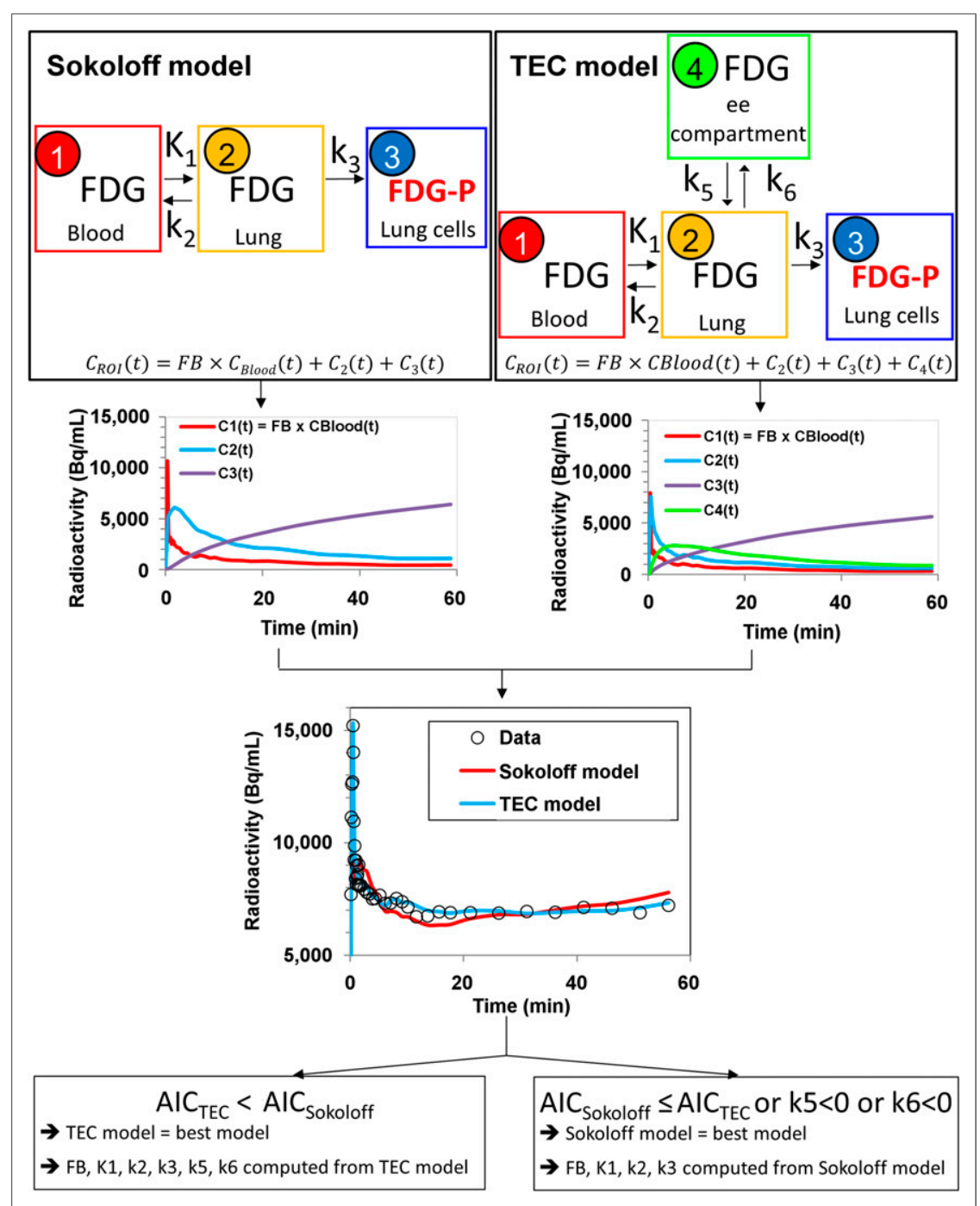

FIGURE 1. Model selection. For each ROI, lung time-activity curves were fitted by use of blood time-activity curve as input function and 2 compartmental models: Sokoloff 3compartment model with 4 parameters $\left(K_{1}, k_{2}, k_{3}\right.$, and FB) (compartment 1: ${ }^{18} \mathrm{~F}-\mathrm{FDG}$ in blood; compartment 2: extravascular ${ }^{18} \mathrm{~F}-\mathrm{FDG}$ in lung tissue; and compartment 3: phosphorylated ${ }^{18} \mathrm{~F}-\mathrm{FDG}$ [FDG-P] entrapped in lung cells) and 4-compartment TEC model with 6 parameters $\left(K_{1}, k_{2}, k_{3}, k_{5}, k_{6}\right.$, and FB) (compartment 1: ${ }^{18} \mathrm{~F}-\mathrm{FDG}$ in blood; compartment 2: extravascular ${ }^{18} \mathrm{~F}-\mathrm{FDG}$ in lung tissue, constituting precursor pool for ${ }^{18} \mathrm{~F}-$ FDG phosphorylation [precursor compartment]; compartment 3: FDG-P entrapped in lung cells [metabolite compartment]; and compartment 4: extravascular extracellular [ee] ${ }^{18} \mathrm{~F}-\mathrm{FDG}$ not directly available for phosphorylation [extravascular noncellular compartment]). Tracer concentration originating from each compartment- $C_{1}(t), C_{2}(t), C_{3}(t)$ and, eventually $\mathrm{C}_{4}(\mathrm{t})$ - over time was computed by compartmental modeling; sum of tracer concentrations in compartments over time was equal to tracer concentration in lung $\mathrm{ROI}$ assessed with $\mathrm{PET}-\mathrm{C}_{\mathrm{ROI}}(\mathrm{t})$. Tracer concentration in blood compartment in lung $\mathrm{ROI}-\mathrm{C}_{1}(\mathrm{t})$ - was computed as $\mathrm{FB}$ in $\mathrm{RO}$ times tracer concentration in blood $\left(\mathrm{C}_{\mathrm{Blood}}\right)$ in left ventricle, as measured with PET, corrected for spillover and partial-volume effects. TEC model was chosen over Sokoloff model (17) if values computed for both $k_{5}$ and $k_{6}$ were positive (because negative values are unrealistic) and if Akaike information criterion (AIC) of TEC model was lower than AIC of Sokoloff model (AIC being tradeoff between goodness of fit and number of parameters required by parsimony).

mode with a constant inspiratory flow $\left(\mathrm{V}_{\mathrm{T}}\right.$ of $\left.10 \mathrm{~mL} \cdot \mathrm{kg}^{-1}\right)$ and an inspired fraction of oxygen of $21 \%$. Muscle relaxation was obtained with pancuronium bromide. The right jugular vein was cannulated with a 3-lumen 8.5-French catheter for drug and tracer administration.

\section{Protocol}

The animals were randomized into 3 groups ( $n=10$ each) in which ALI was induced by $\mathrm{HCl}$ inhalation. Also included were a control group that did not have ALI $(n=6)$ and 2 additional groups $(n=9$ each) that had ventilator-induced lung injury (VILI) caused by injurious ventilator settings and that either received $\mathrm{HCl}$ inhalation or did not receive $\mathrm{HCl}$ inhalation. In the ALI groups and the group that had VILI and received $\mathrm{HCl}$ inhalation, lung injury was induced by intratracheal instillation of $0.1 \mathrm{M} \mathrm{HCl}$ at $3 \mathrm{~mL} \cdot \mathrm{kg}^{-1}$ and was considered to have been achieved when the ratio of $\mathrm{PaO}_{2}$ to the inspired fraction of oxygen was less than $40 \mathrm{kPa}(300 \mathrm{~mm} \mathrm{Hg})$. Additional aliquots of $1 \mathrm{~mL} \cdot \mathrm{kg}^{-1}$ might be administered until the oxygenation target was reached. The PEEP was then set at $3 \mathrm{~cm}$ of $\mathrm{H}_{2} \mathrm{O}$, and $120 \mathrm{~min}$ were allowed for stabilization.

Pressure-volume curves were obtained for the ALI groups and fitted to a sigmoid equation (19) to determine the pressure of maximum decrease in compliance and the pressure at the inflection point. The animals were allocated to the following groups: 2 low-PEEP groups, in which the PEEP was set at $2 \mathrm{~cm}$ of $\mathrm{H}_{2} \mathrm{O}$ above the pressure at the inflection point in the supine and prone positions, and 1 highPEEP group, in which the PEEP was set at 2 $\mathrm{cm}$ of $\mathrm{H}_{2} \mathrm{O}$ above the pressure of maximum decrease in compliance in the supine position. In each group, the plateau pressure of the respiratory system was maintained at less than or equal to $30 \mathrm{~cm}$ of $\mathrm{H}_{2} \mathrm{O}$ by changing the $\mathrm{V}_{\mathrm{T}}$, and the $\mathrm{pH}$ was maintained at more than 7.20 by increasing the respiratory rate; the animals were monitored for $2 \mathrm{~h}$.

In the control group, the PEEP was set at $3 \mathrm{~cm}$ of $\mathrm{H}_{2} \mathrm{O}$, and PET was performed immediately after animals were prepared. In the group that had VILI and did not receive $\mathrm{HCl}$ inhalation and the group that had VILI and received $\mathrm{HCl}$ inhalation, the $\mathrm{V}_{\mathrm{T}}$ was increased from a PEEP of $0 \mathrm{~cm}$ of $\mathrm{H}_{2} \mathrm{O}$ to achieve a transpulmonary pressure of greater than $35 \mathrm{~cm}$ of $\mathrm{H}_{2} \mathrm{O}$ for $2 \mathrm{~h}$ immediately after animal preparation and $2 \mathrm{~h}$ after $\mathrm{HCl}$ instillation, respectively.

One pig in each of the low-PEEP groups, 2 pigs in the high-PEEP group, and 3 pigs in each of the VILI groups died during the study and were excluded from analysis, leaving 44 animals available for analysis.

\section{PET Imaging Protocol}

PET measurements were obtained with an ECAT EXACT HR+ scanner (Siemens). First, PET transmission scans were performed with a rotating ${ }^{68} \mathrm{Ge}$ positron source for tissue attenuation map determination. ${ }^{15} \mathrm{O}-\mathrm{H}_{2} \mathrm{O}$ emission scans were performed after intravenous injection of the tracer at $362 \pm 21$ (mean $\pm \mathrm{SD}$ ) $\mathrm{MBq}$ over 1 min (2). Finally, ${ }^{18} \mathrm{~F}-\mathrm{FDG}$ emission scans were performed after intravenous injection of the tracer at $178 \pm 25 \mathrm{MBq}$ over $30 \mathrm{~s}$. From the start of ${ }^{18} \mathrm{~F}$-FDG 
injection, twenty 5-s PET images, six 30-s images, six 60-s images, four 120-s images, and eight 300-s images were acquired serially. Two milliliters of blood were taken serially through a systemic arterial line during ${ }^{18} \mathrm{~F}-\mathrm{FDG}$ image acquisition. The plasma radioactivity was measured in a well counter cross-calibrated with the PET camera, and the plasma activities of samples taken at 3 and $50 \mathrm{~min}$ after the start of ${ }^{18} \mathrm{~F}$ FDG injection were used to calibrate the blood-pool region of interest (ROI) located in the left ventricle and to obtain an image-derived input function taking into account partial-volume and spillover effects (17).

\section{PET Data Processing}

ROIs were drawn around both lungs on transmission scans, superimposed onto ${ }^{15} \mathrm{O}-\mathrm{H}_{2} \mathrm{O}$ equilibrium images, and then refined to include poorly ventilated dependent lung areas. Refined ROIs were superimposed onto emission images to obtain a lung time-activity curve for each tracer. Ten lung regions with the same vertical height (bins) in the ventral-to-dorsal direction were defined for regional analyses.

PBF was assessed in each lung region by fitting ${ }^{15} \mathrm{O}-\mathrm{H}_{2} \mathrm{O}$ timeactivity curves to a single-compartment model $(2,3)$. Lung regional ${ }^{18} \mathrm{~F}$ FDG kinetics and the ${ }^{18} \mathrm{~F}$-FDG image-derived input function were fitted to both the Sokoloff 3-compartment model (16) and a 4-compartment model incorporating an extravascular noncellular compartment (TEC model) (Fig. 1) (17). The TEC model may be more relevant than the Sokoloff model for edematous lung regions because the former accounts for an (additional) extravascular noncellular compartment spatially disconnected from cells trapping ${ }^{18}$ F-FDG. However, the Sokoloff model is more appropriate for lung regions lacking an extravascular noncellular ${ }^{18} \mathrm{~F}-\mathrm{FDG}$ pool (presumably nonedematous lung regions).

Model parameters were estimated with a generalized least squares algorithm and an autoregressive Laplacian filter $(17,20)$. For each timeactivity curve, model rate constants and FB were computed from the model with the best fit across the data (Appendix). The best model was selected as the model with the lowest Akaike information criterion (17).

\section{Data and Statistical Analysis}

Because regional PBF and FB values are expressed in different units $\left(\mathrm{mL} \cdot \mathrm{min}^{-1} \cdot 100 \mathrm{~mL}\right.$ of lung ${ }^{-1}$ and $\mathrm{mL}$ of blood $100 \mathrm{~mL}$ of lung $^{-1}$, respectively), they were normalized on the basis of the sum of their 10 regional values in each experimental condition, so that normalized values represented the fraction of PBF or FB in a particular region relative to the whole lung.

Values are expressed as mean $\pm \mathrm{SD}$. Correlation between measurements was tested by linear regression. Agreement between PBF assessed on ${ }^{15} \mathrm{O}-\mathrm{H}_{2} \mathrm{O}$ scans and $\mathrm{FB}$ assessed on ${ }^{18} \mathrm{~F}-\mathrm{FDG}$ scans as a surrogate for lung perfusion was tested with the Bland-Altman method for repeated measurements (21). The level of statistical significance was set at less than 0.05 .

\section{RESULTS}

Absolute values of PBF and FB (i.e., before normalization) were correlated $\left(R^{2}=0.63 ; P<0.001\right.$; data not shown). After normalization, the correlation increased $\left(R^{2}=0.90 ; P<0.001\right)$; the slope of the regression line was close to unity, and the intercept was negligible (Fig. 2). Bias was 0, limits of agreement were -0.035 to 0.035 (i.e., $\pm 3.5 \%$ of total lung PBF), and the pattern of residuals exhibited no evidence for heteroscedasticity (Fig. 3).

Regional PBF and FB values remained correlated in each experimental group $(P<0.001)$, with $R^{2}$ of 0.76 in the group that had VILI and received $\mathrm{HCl}$ inhalation, 0.86 in the lowPEEP group in the prone position, 0.95 in the high-PEEP group in the supine position, and 0.96 in the other 3 groups (data not shown). In each experimental group, bias was 0 , and the limits of agreement were -0.02 to $0.02,-0.03$ to 0.03 , or -0.07 to 0.07

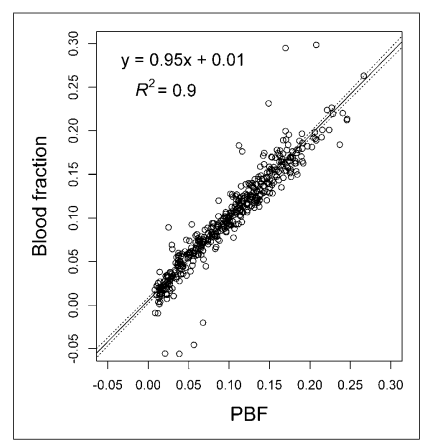

FIGURE 2. Relationship between regional $\mathrm{PBF}$ and $\mathrm{FB}$. $\mathrm{PBF}$ and $\mathrm{FB}$ in each region were expressed as fractions of their values in whole lung. Each symbol represents lung region. Ten lung regions were studied in each of 44 pigs, for total of 440 lung regions. Solid line is regression line. Broken lines are 95\% confidence intervals of predicted values.

both normal animals and animals with lung injury and over wide ranges of $\mathrm{V}_{\mathrm{T}}$ and PEEP values. Taken together, these findings encourage the use of this technique to assess PBF when ${ }^{18} \mathrm{~F}$-FDG PET is performed.

The present study has several strengths. First, the method that we used as the reference method (PET with ${ }^{15} \mathrm{O}-\mathrm{H}_{2} \mathrm{O}$ ) can be considered to be the gold standard for quantifying $\mathrm{PBF}$ in living subjects. Indeed, to our knowledge, PET with ${ }^{15} \mathrm{O}-\mathrm{H}_{2} \mathrm{O}$ is the only imaging technique that has the potential to quantify PBF and that has been formally validated against radioactive microspheres $(2,3)$. Furthermore, the present study is the first to attempt to quantify PBF with ${ }^{18}$ F-FDG. Mullani et al. (22) previously compared PBF assessed with ${ }^{15} \mathrm{O}-\mathrm{H}_{2} \mathrm{O}$ and ${ }^{18} \mathrm{~F}-\mathrm{FDG}$ in solid tumors in various organs using a simple single-compartment model under the assumption of complete first-pass tracer extraction during the first

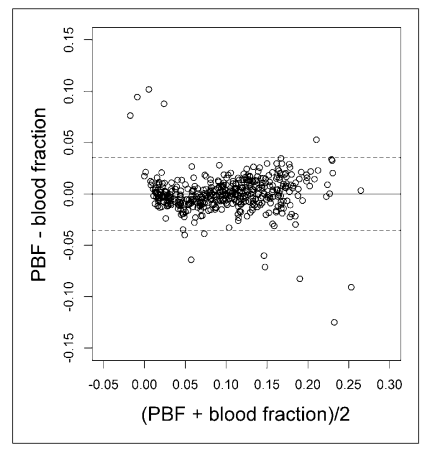

FIGURE 3. Assessment of bias between regional PBF and FB with Bland-Altman representation. PBF and FB in each region were expressed as fraction of their values in whole lung. Each symbol represents lung region. Solid line and broken lines are mean and $95 \%$ confidence interval limits of difference between $\mathrm{PBF}$ and FB, respectively.
2 min after tracer injection. The authors found a good correlation $\left(R^{2}=0.74\right)$ between methods but excluded regions with blood flow greater than $70 \mathrm{~mL} \cdot \mathrm{min}^{-1} \cdot 100 \quad \mathrm{~g}^{-1}$ (whereas PBF may exceed $2,000 \quad \mathrm{~mL} \cdot \mathrm{min}^{-1} \cdot 100 \quad \mathrm{~g}^{-1}$ $(23,24))$. For locally advanced breast cancer, Tseng et al. (25) found significant correlations $\left(R^{2}\right.$ values of 0.38 and 0.66 before and after chemotherapy, respectively) between PBF assessed with ${ }^{15} \mathrm{O}-\mathrm{H}_{2} \mathrm{O}$ and the ${ }^{18} \mathrm{~F}-\mathrm{FDG}$ transport rate constant from blood to tissue $\left(K_{1}\right)$ when they used a 3-compartment model with a fixed FB (4 mL of blood 100 $\mathrm{mL}$ of lung $\left.{ }^{-1}\right)$. This approach is not suitable for the lung because blood volumes are 


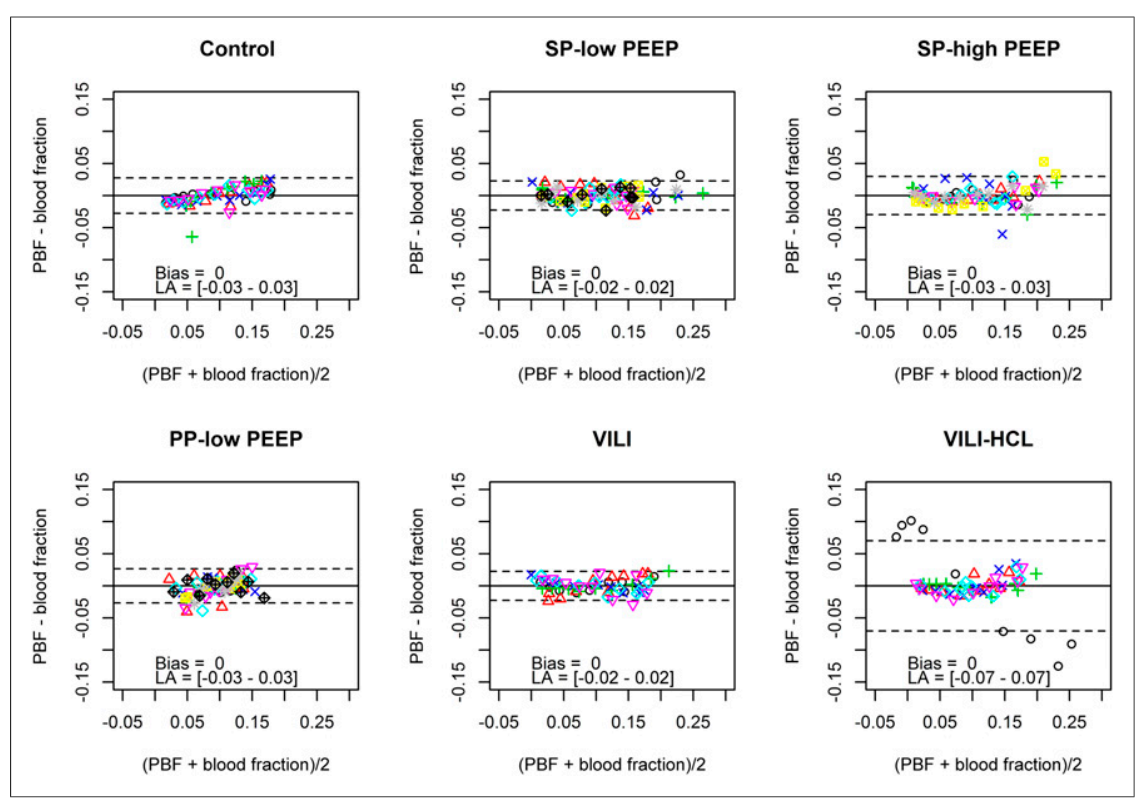

FIGURE 4. Assessment of bias between regional PBF and FB in each experimental group with Bland-Altman representation. PBF and FB in each region were expressed as fractions of their values in whole lung. Each symbol represents lung region, and lung regions in same animal are represented by same symbol in each experimental group. Solid line and broken lines are mean and 95\% confidence interval limits of difference between PBF and FB, respectively. $L A=$ limits of agreement; $P P=$ prone position; $S P=$ supine position, $V I L I=V I L I$ group without $\mathrm{HCl}$; VILI- $\mathrm{HCl}=\mathrm{VILI}$ group with $\mathrm{HCl}$.

highly variable across lung regions (ranging from $0-25 \mathrm{~mL}$ of blood $100 \mathrm{~mL}$ of lung ${ }^{-1}$ ) (Table 1 ) and are influenced by mechanical ventilation settings. Zasadny et al. (26) found a significant correlation $\left(R^{2}=0.71\right)$ between blood flow assessed with ${ }^{15} \mathrm{O}-\mathrm{H}_{2} \mathrm{O}$ and ${ }^{18} \mathrm{~F}-\mathrm{FDG} K_{1}$ when they used a 3-compartment model for breast cancer; that result was not replicated in the present study $\left(R^{2}=\right.$ 0 ; data not shown).

Although the underlying cause of this discrepancy remains speculative, it could be explained by the fact that $K_{1}$ may be used only as a surrogate measurement for blood flow if the tracer permeability-surface area product is large relative to blood flow (27). Although the distribution of water and, hence, ${ }^{15} \mathrm{O}-\mathrm{H}_{2} \mathrm{O}$ has repeatedly been shown to be flow limited rather than diffusion limited, even at high blood flow $(28,29)$, the tracer permeabilitysurface area product for glucose and, hence, ${ }^{18} \mathrm{~F}-\mathrm{FDG}$ is substantially lower than that of water $(29,30)$. The latter data suggest that ${ }^{18} \mathrm{~F}-\mathrm{FDG}$ is a diffusion-limited tracer, even at relatively low blood flow (20-40 $\mathrm{mL} \cdot \mathrm{min}^{-1} \cdot 100 \mathrm{~g}^{-1}$ ) (29). Furthermore, because PBF may exceed $2,000 \mathrm{~mL} \cdot \mathrm{min}^{-1} \cdot 100 \mathrm{~g}^{-1}$, it may largely overcome the blood flow of other organs $(23,24)$, whereas myocardial blood flow at exercise in humans amounts to $200-250 \mathrm{~mL} \cdot \mathrm{min}^{-1} \cdot 100 \mathrm{~g}^{-1}(31)$. Therefore, the ${ }^{18} \mathrm{~F}$-FDG diffusion problem may be even more prominent in the lung when $K_{1}$ is to be used to quantify PBF.

First-pass ${ }^{18} \mathrm{~F}-\mathrm{FDG}$ uptake is another option for quantifying blood flow with PET and the simple blood-flow model (32) and has been shown to correlate well with blood flow assessed with ${ }^{15} \mathrm{O}-\mathrm{H}_{2} \mathrm{O}$ in tumors (22). However, low first-pass ${ }^{18} \mathrm{~F}-\mathrm{FDG}$ extraction, significant venous egress, and trapping of phosphorylated ${ }^{18} \mathrm{~F}-\mathrm{FDG}$ during image acquisition are well-known limitations of this model (22), among others, and may explain the mild correlation between first-pass ${ }^{18} \mathrm{~F}$-FDG uptake and $\mathrm{PBF}$ assessed with ${ }^{15} \mathrm{O}-\mathrm{H}_{2} \mathrm{O}$ in the present study $\left(R^{2}=0.56\right.$; data not shown). Other strengths of the present study are the extremely wide range of regional $\mathrm{PBF}$ values achieved (2 orders of magnitude) (Table 1) and the high reliability of PBF assessment.

Nevertheless, the present study has limitations. First, FB is not a direct estimate of $\mathrm{PBF}$ but may be more related to regional blood volume. However, FB should be viewed as the main determinant of $\mathrm{PBF}$, because $90 \%$ of PBF variance in the present study could be explained by variations in FB as a consequence of an $R^{2}$ of 0.90 . Should other parameters influence PBF, their contributions would be minor and should not alter significantly the relationship between PBF and FB. Because the central volume principle states that $\mathrm{PBF}$ equals blood volume divided by mean transit time, the good correlation between normalized FB and PBF in the present study suggested that mean pulmonary transit times were not significantly different among lung regions. Whether this phenomenon exists in patients with ALI remains speculative, but it was previously observed in healthy people during exercise (33). Interestingly, the same excellent correlation $\left(R^{2}=0.84\right)$ between blood flow and blood volume was recently found in anesthetized, mechanically ventilated pigs (34). A weaker, although significant, correlation between lung perfusion and pulmonary blood volume $\left(R^{2}=0.50\right)$ assessed with MR imaging was also found in 23 patients (35). These data might suggest that our findings can be extrapolated to patients.

Another limitation of the present study is that FB had to be normalized to improve the correlation with PBF, suggesting significant variability among the animals in the study. Nevertheless, absolute values for regional PBF can be easily obtained by combining relative PBF measurements with a noninvasive estimation of absolute cardiac output by use of echocardiography (36) or bioimpedance $(37,38)$. Furthermore, PBF normalization is often required to control for changes in cardiac output between subjects or between time points when multiple measurements are successively obtained in the same subject. Finally, the ventilationto-perfusion ratio cannot be assessed directly with ${ }^{18} \mathrm{~F}-\mathrm{FDG}$ scans, but this technique would be feasible with PET/CT and quantitative evaluation of $\mathrm{V}_{\mathrm{T}}$ distribution by density analysis (39).

A final limitation is that multicompartmental modeling requires extensive computer resources, precluding a voxel-by-voxel analysis of FB and, hence, lung perfusion; however, this problem may be overcome in the near future.

The clinical implications of using FB to quantify PBF may be important. First, this new method could be used in all PET facilities, eliminating the need for a dedicated cyclotron on site. Second, this method makes it possible to study ventilation, perfusion, and lung inflammation with a single tracer (i.e., ${ }^{18}$ F-FDG) and with a single PET/CT acquisition. In the specific context of ALI, such studies would allow the regional quantification not only of alveolar recruitment but also of functional recruitment (alveolar recruitment of perfused lung regions) in combination with an evaluation of neutrophil-related lung inflammation. 


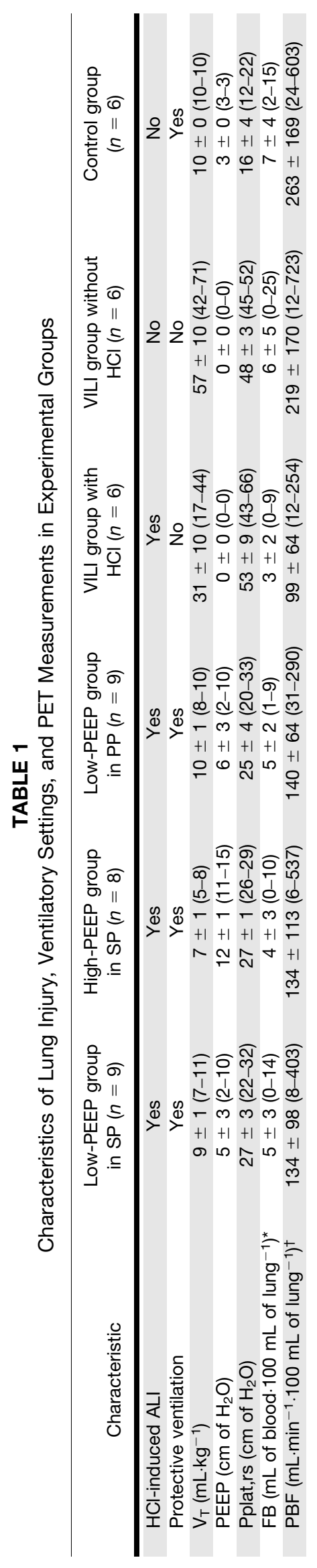

\section{CONCLUSION}

Estimating PBF from FB measured with ${ }^{18} \mathrm{~F}-\mathrm{FDG}$ PET has been demonstrated to provide results comparable to those obtained with the current, noninvasive gold standard (PET with ${ }^{15} \mathrm{O}-\mathrm{H}_{2} \mathrm{O}$ ). This new method is reliable in both normal animals and animals with ALI. Hybrid devices combining PET and CT have the potential to allow the study of ventilation, perfusion, and lung inflammation with a single tracer.

\section{APPENDIX}

\section{TEC Model (Fig. 1)}

Changes in ${ }^{18} \mathrm{~F}-\mathrm{FDG}$ concentrations over time in blood $\left[\mathrm{C}_{\text {Blood }}(\mathrm{t})\right]$, precursor $\left[\mathrm{C}_{\mathrm{e}}(\mathrm{t})\right]$, metabolite $\left[\mathrm{C}_{\mathrm{m}}(\mathrm{t})\right]$, and extravascular noncellular $\left[\mathrm{C}_{\mathrm{ee}}(\mathrm{t})\right]$ compartments may be described with the following differential equations:

$$
\begin{array}{cc}
\dot{C}_{e}(t)=K_{1} \cdot C_{\text {Blood }}(t)-\left(k_{2}+k_{3}+k_{5}\right) \cdot C_{e}(t)+k_{6} \cdot C_{e e}(t), & \text { Eq. } 1 \\
\dot{C}_{e e}(t)=k_{3} \cdot C_{e}(t), & \text { Eq. } 2 \\
\dot{C}_{m}(t)=k_{5} \cdot C_{e}(t)-k_{6} \cdot C_{e e}(t), & \text { Eq. } 3
\end{array}
$$

Furthermore, the sum of tracer concentrations in the compartments is equal to the tracer concentration in a lung ROI assessed with $\operatorname{PET}\left[\mathrm{C}_{\mathrm{ROI}}(\mathrm{t})\right]$ :

$$
C_{R O I}(t)=F B \cdot C_{\text {Blood }}(t)+C_{e}(t)+C_{e e}(t)+C_{m}(t), \quad \text { Eq. } 4
$$

Substituting, applying Laplace transformation, and rearranging yields (with initial conditions assumed to be 0 ):

$$
\begin{aligned}
s^{3} C_{R O I}(s)= & a_{1} \cdot s^{2} C_{R O I}(s)+a_{2} \cdot s C_{R O I}(s)+a_{3} \cdot s^{3} C_{\text {Blood }}(s) \\
& +a_{4} \cdot s^{2} C_{\text {Blood }}(s)+a_{5} \cdot s C_{\text {Blood }}(s)+a_{6} \cdot C_{\text {Blood }}(s)
\end{aligned}
$$

with $a_{1}=-\left(k_{2}+k_{3}+k_{5}+k_{6}\right), a_{2}=-k_{6} \cdot\left(k_{2}+k_{3}\right), a_{3}=$ $F B, a_{4}=\left(k_{2}+k_{3}+k_{5}+k_{6}\right) \cdot F B+K_{1}, a_{5}=K_{1} \cdot\left(k_{3}+k_{5}+k_{6}\right)$ $+F B \cdot k_{6} \cdot\left(k_{2}+k_{3}\right)$, and $a_{6}=K_{1} \cdot k_{3} \cdot k_{6}$.

Applying inverse Laplace transformation and integrating 3 times with initial conditions assumed to be 0 yields:

$$
\begin{aligned}
C_{R O I}(t)= & a_{1} \cdot \int_{0}^{t} C_{R O I}(\tau) d \tau+a_{2} \cdot \int_{0}^{t} \int_{0}^{\tau} C_{R O I}(s) d s d \tau+a_{3} \cdot C_{\text {Blood }}(t) \\
& +a_{4} \cdot \int_{0}^{t} C_{\text {Blood }}(\tau) d \tau+a_{5} \cdot \int_{0}^{t} \int_{0}^{\tau} C_{\text {Blood }}(s) d s d \tau \\
& +a_{6} \cdot \int_{0}^{t} \int_{0}^{\tau} \int_{0}^{s} C_{\text {Blood }}(u) d u d s d \tau,
\end{aligned}
$$

Eq. 6

Estimates of $a_{1}$ and $a_{2}\left(\hat{a}_{1}\right.$ and $\left.\hat{a}_{2}\right)$ are obtained by solving Equation 6 with a linear least squares method $(17,40)$. These estimates are biased because the errors in Equation 6 are correlated (40).

An autoregressive filter $\left(s^{3}-\hat{a}_{1} \cdot s^{2}-\hat{a}_{2} \cdot s\right)$ is then defined by rearranging Equation 5 : 


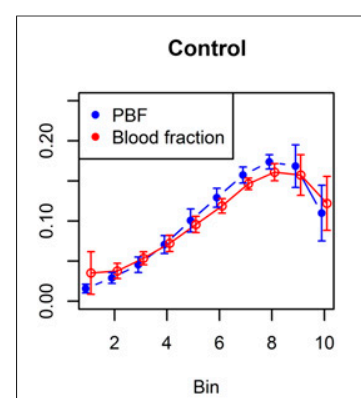

PP-IOW PEEP

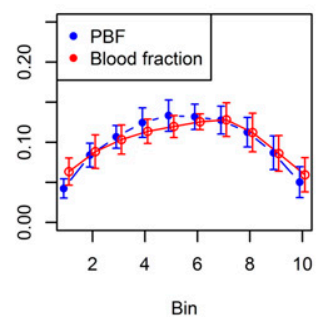

SP-low PEEP

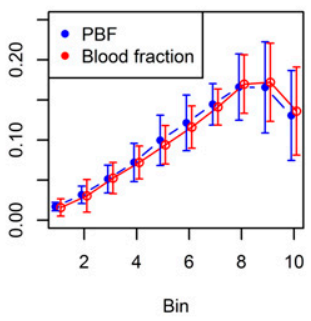

VILI

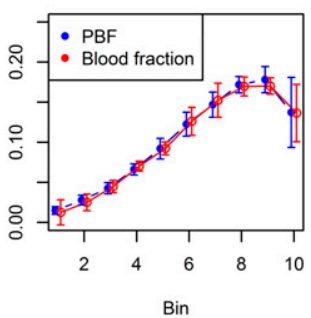

Bin
SP-high PEEP

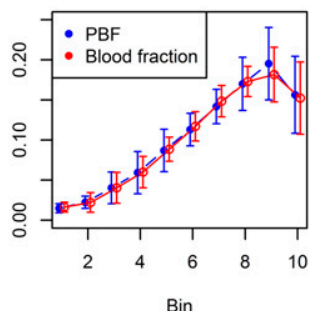

VILI-HCL

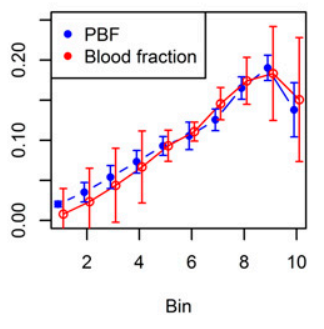

FIGURE 5. Anterior-to-posterior distribution of PBF (blue circles) and FB (red circles) in each experimental group. PBF and FB in each region were expressed as fractions of their values in whole lung. Circles represent means, and bars represent standard deviations. Bins are lung regions with same vertical heights along ventral-to-dorsal direction. Lower bins are more ventrally located, and higher bins are more dorsally located. PP = prone position; SP = supine position; VILI = VILI group without $\mathrm{HCl}$; VILI- $\mathrm{HCl}=\mathrm{VILI}$ group with $\mathrm{HCl}$.
Solving Equation 8 with the generalized linear least squares algorithm yields unbiased estimates of $a_{1}, a_{2}, a_{3}, a_{4}, a_{5}$, and $a_{6}$.

Once the macroparameters are obtained, the rate constants may be obtained as follows:

$$
\begin{gathered}
\mathrm{FB}=a_{3}, \quad K_{1}=a_{4}+a_{1} \cdot a_{3}, \\
k_{2}=-\frac{a_{5}+a_{2} \cdot a_{3}}{a_{1} \cdot a_{3}+a_{4}}-a_{1}, \\
k_{3}=-\frac{k_{2} \cdot a_{6}}{a_{6}+K_{1} \cdot a_{2}}, \\
k_{6}=-\frac{a_{6}+K_{1} \cdot a_{2}}{K_{1} \cdot k_{2}}, \text { and } \\
k_{5}=-\left(k_{2}+k_{3}+k_{6}+a_{1}\right) .
\end{gathered}
$$

\section{Sokoloff Model (Fig. 1)}

Changes in ${ }^{18} \mathrm{~F}-\mathrm{FDG}$ concentrations over time in blood $\left[\mathrm{C}_{\mathrm{Blood}}(\mathrm{t})\right]$, precursor $\left[\mathrm{C}_{\mathrm{e}}(\mathrm{t})\right]$, and metabolite $\left[\mathrm{C}_{\mathrm{m}}(\mathrm{t})\right]$ compartments may be described with the following differential equations:

$$
\dot{C}_{e}(t)=K_{1} \cdot C_{\text {Blood }}(t)-\left(k_{2}+k_{3}\right) \cdot C_{e}(t),
$$

Eq. 9

$$
\dot{C}_{m}(t)=k_{3} \cdot C_{e}(t),
$$

Eq. 10

$$
\begin{aligned}
& \frac{s^{3} C_{\mathrm{ROI}}(s)}{\left(s^{3}-\hat{a}_{1} \cdot s^{2}-\hat{a}_{2} \cdot s\right)} \\
& =\frac{a_{1} \cdot s^{2} C_{\mathrm{ROI}}(s)}{\left(s^{3}-\hat{a}_{1} \cdot s^{2}-\hat{a}_{2} \cdot s\right)} \\
& +\frac{a_{2} \cdot s C_{\mathrm{ROI}}(s)}{\left(s^{3}-\hat{a}_{1} \cdot s^{2}-\hat{a}_{2} \cdot s\right)} \\
& +\frac{a_{3} \cdot s^{3} C_{\text {Blood }}(s)}{\left(s^{3}-\hat{a}_{1} \cdot s^{2}-\hat{a}_{2} \cdot s\right)} \\
& +\frac{a_{4} \cdot s^{2} C_{\mathrm{Blood}}(s)}{\left(s^{3}-\hat{a}_{1} \cdot s^{2}-\hat{a}_{2} \cdot s\right)} \\
& +\frac{a_{5} \cdot s C_{\text {Blood }}(s)}{\left(s^{3}-\hat{a}_{1} \cdot s^{2}-\hat{a}_{2} \cdot s\right)} \\
& +\frac{a_{6} \cdot C_{\text {Blood }}(s)}{\left(s^{3}-\hat{a}_{1} \cdot s^{2}-\hat{a}_{2} \cdot s\right)},
\end{aligned}
$$

Eq. 7

Rearranging and applying inverse Laplace transformation yields:

$$
\begin{gathered}
\begin{array}{c}
C_{\mathrm{ROI}}(t)+\hat{a}_{1} \cdot \psi_{1} \otimes C_{\mathrm{ROI}}(t)+\hat{a}_{2} \cdot \psi_{2} \otimes C_{\mathrm{ROI}}(t) \\
=a_{1} \cdot \psi_{1} \otimes C_{\mathrm{ROI}}(t)+a_{2} \cdot
\end{array} \\
\begin{aligned}
\psi_{2} \otimes C_{\mathrm{ROI}}(t)+a_{3} \cdot\left[C_{\mathrm{Blood}}(t)+\hat{a}_{1} \cdot \psi_{1} \cdot \otimes C_{\mathrm{Blood}}(t)\right. \\
\left.+a_{2} \cdot \psi_{2} \otimes C_{\mathrm{Blood}}(t)\right]+a_{4} \cdot
\end{aligned} \\
\begin{array}{r}
\psi_{1} \otimes C_{\mathrm{Blood}}(t)+a_{5} \cdot \psi_{2} \otimes C_{\mathrm{Blood}}(t)+a_{6} \cdot \psi_{3} \otimes C_{\mathrm{Blood}}(t), \\
\text { with } \quad \lambda_{1,2}=\frac{\hat{a}_{1} \pm \sqrt{\hat{a}_{1}+4 \hat{a}_{2}}}{2}, \quad \psi_{1}=\frac{1}{\left(\lambda_{2}-\lambda_{1}\right)}\left(\lambda_{2} e^{\lambda_{2} t}-\lambda_{1} e^{\lambda_{1} t}\right),
\end{array} \\
\begin{array}{l}
\psi_{2}=\frac{1}{\left(\lambda_{2}-\lambda_{1}\right)}\left(e^{\lambda_{2} t}-e^{\lambda_{1} t}\right), \text { and } \psi_{3}=\frac{e^{\lambda_{2} t}}{\lambda_{2}\left(\lambda_{2}-\lambda_{1}\right)}+\frac{1}{\lambda_{1} \lambda_{2}}- \\
\frac{e^{\lambda_{1} t}}{\lambda_{1}\left(\lambda_{2}-\lambda_{1}\right)}
\end{array}
\end{gathered}
$$

The sum of tracer concentrations in the compartments is equal to the tracer concentration in a lung ROI assessed with PET $\left[\mathrm{C}_{\mathrm{ROI}}(\mathrm{t})\right]$ :

$$
C_{R O I}(t)=F B \cdot C_{\text {Blood }}(t)+C_{e}(t)+C_{m}(t),
$$

Eq. 11

Substituting, applying Laplace transformation, and rearranging yields:

$$
\begin{aligned}
s^{2} C_{\mathrm{ROI}}(s)= & a_{1} \cdot s^{2} C_{\text {Blood }}(s)+a_{2} \cdot s C_{\mathrm{Blood}}(s) \\
& +a_{3} \cdot C_{\text {Blood }}(s)+a_{4} \cdot s C_{\mathrm{ROI}}(s),
\end{aligned}
$$

Eq. 12

with $a_{1}=F B, \quad a_{2}=\left(k_{2}+k_{3}\right) \cdot F B+K_{1}, \quad a_{3}=K_{1} \cdot k_{3}, \quad$ and $a_{4}=-\left(k_{2}+k_{3}\right)$.

Applying inverse Laplace transformation and integrating 2 times with initial conditions assumed to be 0 yields:

$$
\begin{aligned}
C_{\text {ROI }}(t)= & a_{1} \cdot C_{\text {Blood }}(t)+a_{2} \cdot \int_{0}^{t} C_{\text {Blood }}(\tau) d \tau \\
& +a_{3} \cdot \int_{0}^{t} \int_{0}^{\tau} C_{\text {Blood }}(s) d s d \tau+a_{4} \cdot \int_{0}^{t} C_{R O I} d \tau,
\end{aligned}
$$

Eq. 13

An estimate of $a_{4}\left(\hat{a}_{4}\right)$ is obtained by solving Equation 13 with a linear least squares method (40). 
An autoregressive filter $\left(s^{2}-\hat{a}_{4} \cdot s\right)$ is then defined by rearranging Equation 12:

$$
\begin{aligned}
\frac{s^{2} C_{R O I}(s)}{\left(s^{2}-\hat{a}_{4} \cdot s\right)}= & \frac{a_{1} \cdot s^{2} C_{\text {Blood }}(s)}{\left(s^{2}-\hat{a}_{4} \cdot s\right)}+\frac{a_{2} \cdot s C_{\text {Blood }}(s)}{\left(s^{2}-\hat{a}_{4} \cdot s\right)} \\
& +\frac{a_{3} \cdot C_{\text {Blood }}(s)}{\left(s^{2}-\hat{a}_{4} \cdot s\right)}+\frac{a_{4} \cdot s C_{R O I}(s)}{\left(s^{2}-\hat{a}_{4} \cdot s\right)},
\end{aligned}
$$

Rearranging and applying inverse Laplace transformation yields:

$$
\begin{aligned}
& C_{R O I}(t)+\hat{a}_{4} \cdot \psi_{1} \otimes C_{R O I}(t)=a_{1} \cdot C_{\text {Blood }}(t)+a_{1} \cdot \hat{a}_{4} \\
& \cdot \cdot \psi_{1} \otimes C_{\text {Blood }}(t)+a_{2} \cdot \psi_{1} \otimes C_{\text {Blood }}(t)+a_{3} \cdot \psi_{2} \otimes C_{\text {Blood }}(t)+a_{4} \\
& \cdot \psi_{1} \otimes C_{R O I}(t),
\end{aligned}
$$

with $\psi_{1}=e^{\hat{a}_{4} t}, \psi_{2}=\frac{e^{\hat{a}_{4} t}-1}{\hat{a}_{4}}$.

Eq. 15

Solving Equation 15 with the generalized linear least squares algorithm yields unbiased estimates of $a_{1}, a_{2}, a_{3}$, and $a_{4}$.

Once the macroparameters are obtained, the rate constants may be obtained as follows:

$$
\begin{aligned}
\mathrm{FB} & =a_{1}, K_{1}=a_{1} \cdot a_{4}+a_{2}, k_{2}=-\left(\frac{a_{3}}{a_{1} \cdot a_{4}+a_{2}}\right)-a_{4}, \text { and } \\
k_{3} & =-\left(k_{2}+a_{4}\right) .
\end{aligned}
$$

\section{DISCLOSURE}

The costs of publication of this article were defrayed in part by the payment of page charges. Therefore, and solely to indicate this fact, this article is hereby marked "advertisement" in accordance with 18 USC section 1734. Financial support for this study was provided by Université de Lyon, Lyon, France, and Bourse de Recherche Expérimentale de la Société de Réanimation de Langue Française (SRLF). We thank IBA Co., which provided us with the ${ }^{18}$ F-FDG compound. No other potential conflict of interest relevant to this article was reported.

\section{ACKNOWLEDGMENTS}

We thank Dr. Tobias Schroeder and Dr. Jose G. Venegas (Department of Anesthesia and Critical Care, Massachusetts General Hospital and Harvard Medical School, Boston, MA) for help in implementing compartmental modeling algorithms.

\section{REFERENCES}

1. Petersson J, Sanchez-Crespo A, Rohdin M, et al. Physiological evaluation of a new quantitative SPECT method measuring regional ventilation and perfusion. J Appl Physiol. 2004;96:1127-1136.

2. Mintun MA, Ter-Pogossian MM, Green MA, Lich LL, Schuster DP. Quantitative measurement of regional pulmonary blood flow with positron emission tomography. J Appl Physiol. 1986;60:317-326.

3. Schuster DP, Kaplan JD, Gauvain K, Welch MJ, Markham J. Measurement of regional pulmonary blood flow with PET. J Nucl Med. 1995;36:371-377.

4. Richard JC, Janier M, Decailliot F, et al. Comparison of PET with radioactive microspheres to assess pulmonary blood flow. J Nucl Med. 2002;43:10631071.

5. Jones AT, Hansell DM, Evans TW. Pulmonary perfusion in supine and prone positions: an electron-beam computed tomography study. J Appl Physiol. 2001;90:1342-1348.
6. Dakin J, Jones AT, Hansell DM, Hoffman EA, Evans TW. Changes in lung composition and regional perfusion and tissue distribution in patients with ARDS. Respirology. 2011;16:1265-1272.

7. Hatabu H, Tadamura E, Levin DL, et al. Quantitative assessment of pulmonary perfusion with dynamic contrast-enhanced MR imaging. Magn Reson Med. 1999;42:1033-1038.

8. Hopkins SR, Henderson AC, Levin DL, et al. Vertical gradients in regional lung density and perfusion in the supine human lung: the Slinky effect. J Appl Physiol. 2007;103:240-248.

9. Senda M, Murata K, Itoh H, Yonekura Y, Torizuka K. Quantitative evaluation of regional pulmonary ventilation using PET and nitrogen-13 gas. J Nucl Med. 1986;27:268-273.

10. Richard JC, Janier M, Lavenne F, et al. Quantitative assessment of regional alveolar ventilation and gas volume using ${ }^{13} \mathrm{~N}-\mathrm{N}_{2}$ washout and PET. J Nucl Med. 2005;46:1375-1383.

11. Rhodes CG, Valind SO, Brudin LH, et al. Quantification of regional V/Q ratios in humans by use of PET, II: procedure and normal values. J Appl Physiol. 1989;66:1905-1913.

12. Vidal Melo MF, Layfield D, Harris RS, et al. Quantification of regional ventilation-perfusion ratios with PET. J Nucl Med. 2003;44:1982-1991.

13. Jones HA, Cadwallader KA, White JF, Uddin M, Peters AM, Chilvers ER. Dissociation between respiratory burst activity and deoxyglucose uptake in human neutrophil granulocytes: implications for interpretation of ${ }^{18} \mathrm{~F}$-FDG PET images. J Nucl Med. 2002;43:652-657.

14. Musch G, Venegas JG, Bellani G, et al. Regional gas exchange and cellular metabolic activity in ventilator-induced lung injury. Anesthesiology. 2007; 106:723-735.

15. Richter T, Bellani G, Scott Harris R, et al. Effect of prone position on regional shunt, aeration, and perfusion in experimental acute lung injury. Am J Respir Crit Care Med. 2005;172:480-487.

16. Sokoloff L, Reivich M, Kennedy C, et al. The $\left[{ }^{14} \mathrm{C}\right]$ deoxyglucose method for the measurement of local cerebral glucose utilization: theory, procedure, and normal values in the conscious and anesthetized albino rat. J Neurochem. 1977;28: 897-916.

17. Schroeder T, Vidal Melo MF, Musch G, Harris RS, Venegas JG, Winkler T. Modeling pulmonary kinetics of 2-deoxy-2-[ $\left.{ }^{18} \mathrm{~F}\right]$ fluoro-D-glucose during acute lung injury. Acad Radiol. 2008;15:763-775.

18. Richard JC, Pouzot C, Gros A, et al. Imaging ventilator induced lung injury with PET [abstract]. Intensive Care Med. 2011;37(suppl):S192.

19. Harris RS, Hess DR, Venegas JG. An objective analysis of the pressure-volume curve in the acute respiratory distress syndrome. Am J Respir Crit Care Med. 2000;161:432-439.

20. Feng D, Ho D, Lau KK, Siu WC. GLLS for optimally sampled continuous dynamic system modeling: theory and algorithm. Comput Methods Programs Biomed. 1999;59:31-43.

21. Bland JM, Altman DG. Measuring agreement in method comparison studies. Stat Methods Med Res. 1999;8:135-160.

22. Mullani NA, Herbst RS, O'Neil RG, Gould KL, Barron BJ, Abbruzzese JL. Tumor blood flow measured by PET dynamic imaging of first-pass ${ }^{18}$ F-FDG uptake: a comparison with ${ }^{15} \mathrm{O}-$ labeled water-measured blood flow. $\mathrm{J} \mathrm{Nucl}$ Med. 2008;49:517-523.

23. Richard JC, Decailliot F, Janier M, Annat G, Guérin C. Effects of positive end-expiratory pressure and body position on pulmonary blood flow redistribution in mechanically ventilated normal pigs. Chest. 2002;122:9981005.

24. Parker JC, Ardell JL, Hamm CR, Barman SA, Coker PJ. Regional pulmonary blood flow during rest, tilt, and exercise in unanesthetized dogs. J Appl Physiol. 1995; 78:838-846.

25. Tseng J, Dunnwald LK, Schubert EK, et al. ${ }^{18}$ F-FDG kinetics in locally advanced breast cancer: correlation with tumor blood flow and changes in response to neoadjuvant chemotherapy. J Nucl Med. 2004;45:18291837.

26. Zasadny KR, Tatsumi M, Wahl RL. FDG metabolism and uptake versus blood flow in women with untreated primary breast cancers. Eur J Nucl Med Mol Imaging. 2003;30:274-280.

27. Morris ED, Endres CJ, Schmidt KC, Christian BT, Muzic RF Jr, Fisher RE. Kinetic modeling in positron emission tomography. In: Wernick MN, Aarsvold JN, eds. Emission Tomography: The Fundamentals of PET and SPECT. San Diego, CA: Elsevier Academic Press; 2004:499540 .

28. Bergmann SR, Fox KA, Rand AL, et al. Quantification of regional myocardial blood flow in vivo with $\mathrm{H}_{2}{ }^{15} \mathrm{O}$. Circulation. 1984;70:724-733.

29. Alvarez OA, Yudilevich DL. Heart capillary permeability to lipid-insoluble molecules. J Physiol. 1969;202:45-58. 
30. Kuikka J, Levin M, Bassingthwaighte JB. Multiple tracer dilution estimates of D- and 2-deoxy-D-glucose uptake by the heart. Am J Physiol. 1986;250: H29-H42.

31. Spiller P, Webb-Peploe MM. Blood flow. Eur Heart J. 1985;6(suppl C): 11-18.

32. Mullani NA, Gould KL. First-pass measurements of regional blood flow with external detectors. J Nucl Med. 1983;24:577-581.

33. Zavorsky GS, Walley KR, Russell JA. Red cell pulmonary transit times through the healthy human lung. Exp Physiol. 2003;88:191-200.

34. Fuld MK, Halaweish AF, Haynes SE, Divekar AA, Guo J, Hoffman EA. Pulmonary perfused blood volume with dual-energy $\mathrm{CT}$ as surrogate for pulmonary perfusion assessed with dynamic multidetector CT. Radiology. 2013;267: 747-756.

35. Molinari F, Fink C, Risse F, Tuengerthal S, Bonomo L, Kauczor H-U. Assessment of differential pulmonary blood flow using perfusion magnetic resonance imaging: comparison with radionuclide perfusion scintigraphy. Invest Radiol. 2006;41:624-630.

36. Ihlen H, Amlie JP, Dale J, et al. Determination of cardiac output by Doppler echocardiography. Br Heart J. 1984;51:54-60.
37. Suttner S, Schöllhorn T, Boldt J, et al. Notice of retraction of "Noninvasive assessment of cardiac output using thoracic electrical bioimpedance in hemodynamically stable and unstable patients after cardiac surgery: a comparison with pulmonary artery thermodilution" [retraction of: Suttner S, Schöllhorn T, Boldt J, et al. In: Intensive Care Med. 2006;32:2053-2058]. Intensive Care Med. 2011;37:1232.

38. Suttner S, Schöllhorn T, Boldt J, et al. Noninvasive assessment of cardiac output using thoracic electrical bioimpedance in hemodynamically stable and unstable patients after cardiac surgery: a comparison with pulmonary artery thermodilution [retracted in: Intensive Care Med. 2011;37:1232]. Intensive Care Med. 2006;32:2053-2058.

39. Victorino JA, Borges JB, Okamoto VN, et al. Imbalances in regional lung ventilation: a validation study on electrical impedance tomography. Am J Respir Crit Care Med. 2004;169:791-800.

40. Feng D, Huang SC, Wang ZZ, Ho D. An unbiased parametric imaging algorithm for nonuniformly sampled biomedical system parameter estimation. IEEE Trans Med Imaging. 1996;15:512-518.

\section{Erratum}

In the article "PET Imaging of Proliferation with Pyrimidines," by Tehrani and Shields (J Nucl Med. 2013;54:903912), the structure of FLT depicted in Figure 1 was wrong. Figure 1 lacked the oxygen in the ribose ring of thymidine and FLT but correctly showed the difference between the molecules. The corrected figure appears below. The authors regret the error.<smiles></smiles>

Thymidine<smiles>Cc1cn([C@H]2C[C@@H]3[C@@H](CO)O[C@@H]2C3(F)F)c(=O)[nH]c1=O</smiles>

FLT 